\title{
Proteinuria and its relation to diverse biomarkers and body mass index in chronic hemodialysis
}

This article was published in the following Dove Press journal: International Journal of Nephrology and Renovascular Disease 27 June 2013

Number of times this article has been viewed

\author{
Hernán Trimarchi' \\ Alexis Muryan² \\ María-Soledad Raña' \\ Pedro Paggi ${ }^{2}$ \\ Fernando Lombi' \\ Mariano Forrester ${ }^{1}$ \\ Vanesa Pomeranz' \\ Alejandra Karl' \\ Mirta Alonso ${ }^{2}$ \\ Pablo Young ${ }^{3}$ \\ Mariana Dicugno \\ 'Department of Nephrology, \\ ${ }^{2}$ Department of Biochemistry, \\ ${ }^{3}$ Department of Internal Medicine \\ Services, Hospital Británico de \\ Buenos Aires, Buenos Aires, Argentina
}

Background: Certain adipokines exert direct effects on proteinuria, a cardiovascular risk factor ignored in hemodialysis. We measured different adipokines according to body mass index (BMI) in relation to proteinuria.

Methods: Patients numbered 57: group A (GA), BMI < 25, $\mathrm{n}=22$; GB, BMI 25-30, $\mathrm{n}=15$; and $\mathrm{GC}, \mathrm{BMI}>30, \mathrm{n}=20$. There were no statistical differences in age, sex, time on dialysis, cause of renal failure, diabetes, hypertension, C-reactive protein, or nutritional status. Measures were taken of 24-hour diuresis and proteinuria, ultrafiltration, albumin, pro-brain natriuretic peptide (Pro-BNP), insulin, adiponectin, leptin, and ghrelin.

Results: Proteinuria was significantly higher in GC versus (vs) GA (1.5 g/day, range 0.30-14 vs $0.72 \mathrm{~g} /$ day, range $0.1-2.7 ; P<0.01)$ and correlated significantly with leptin levels $(\rho=0.47$, $P<0.05)$. In GA, elevated levels of Pro-BNP, adiponectin, and ghrelin were associated with lower degrees of proteinuria. Significant correlations were found between adiponectin and leptin ( $\rho=-0.54, P=0.03)$, and adiponectin and Pro-BNP $(\rho=0.59, P=0.02)$. Though not significant, there were more diabetics in GC (GA four, GB three, GC ten). As BMI increased in GB and GC, Pro-BNP, adiponectin, and ghrelin levels decreased significantly, while proteinuria, insulin, and homeostasis model assessment of insulin resistance increased. Leptin levels were significantly elevated in GC vs GA and GB. In GC, ghrelin correlated significantly with Pro-BNP ( $\rho=0.51$, $P=0.03)$, while leptin correlation with Pro-BNP was inverse and significant in GA ( $\rho=-0.74$, $P<0.001)$ and inverse and nonsignificant in GB and GC.

Conclusion: In patients with BMI $<25$, higher adiponectin, ghrelin, and Pro-BNP levels were associated with lower proteinuria and leptinemia. In obesity, hyperleptinemia and hyperinsulinemia associated with higher proteinuria; whether decreased adiponectinghrelin-ProBNP and/or elevated leptin-insulin levels aggravate proteinuria remains to be determined.

Keywords: proteinuria, adiponectin, ghrelin, leptin, Pro-BNP, hemodialysis, BMI

\section{Introduction}

Proteinuria is a predictor of increased cardiovascular risk in the general population and in chronic kidney disease, and also a significant risk factor for hospitalization and all-cause mortality. ${ }^{1-4}$ Numerous studies have shown that treating patients with diabetic/nondiabetic chronic kidney disease and proteinuria reduces proteinuria and slows progression of renal disease, and the greater the proteinuria decrease, the greater the benefit. ${ }^{5,6}$ In addition to predicting chronic kidney disease progression, proteinuria is also linked to insulin resistance, obesity, and oxidant stress. ${ }^{2,7,8}$ However, no data existed about proteinuria as a cardiovascular risk factor in hemodialysis patients until our recent publication, in which we demonstrated an association between higher degrees
Correspondence: Hernán Trimarch Servicio de Nefrología, Hospital Británico de Buenos Aires, 74 Perdriel, Buenos Aires $\mathrm{Cl} 280 \mathrm{AEB}$, Argentina

Tel +54 II 43096400

Fax +54 II 43043393

Email htrimarchi@hotmail.com 
of proteinuria, inflammation, and cardiovascular disease in chronic hemodialysis. We found that nephrotic-range proteinuria was significantly higher in diabetic nephropathy patients on hemodialysis. ${ }^{8}$ Moreover, our group has suggested that according to the previously reported diminished mortality rates that occur in obese hemodialysis patients, this paradox may be related to low pro-brain natriuretic peptide (Pro-BNP) levels, which may in turn be due to the impact of the higher Pro-BNP clearance secondary to a larger adipocyte mass, and also due to potential interactions with adiponectin and other cytokines. As body mass index (BMI) changes, adiponectin levels vary, and their roles and effects may be different. ${ }^{9}$ Later on, we also reported that in low BMI hemodialysis subjects, malnourishment, inflammation, high Pro-BNP and adiponectin, and low myocardial restriction were prevalent, while in the obese, despite higher ultrafiltration rates, Pro-BNP levels remained low, probably causing hypoadiponectinemia, cardiac remodeling, and decreased stretching. ${ }^{10}$

Altogether, this data may show that adiponectin, a supposed cardiovascular protective adipokine, may change its levels and roles depending on the BMI. Consequently, hypoadiponectinemia may render proteinuria progression unhindered. Leptin, an adipokine related to the regulation of food intake and body composition, has been shown to be elevated in hemodialysis subjects, and is positively correlated with adiposity, insulin resistance, and higher BMI. ${ }^{11,12}$ Leptin has also been shown to be involved in the development of glomerulosclerosis and proteinuria. ${ }^{13}$ However, no data exist linking leptin and proteinuria in hemodialysis.

Finally, ghrelin is a peptide secreted by the gastrointestinal tract that is decreased in obese subjects and also participates in food intake and energy balance. ${ }^{14}$ Noteworthy is the fact that albeit proteinuria is a cause of negative energy balance, it has never been considered as another cause of protein energy-wasting syndrome in chronic hemodialysis. In addition, no available data exist assessing proteinuria and ghrelin in dialysis. Is proteinuria in hemodialysis just a consequence of most causes of end-stage renal disease, or is it also a cause of systemic inflammation and vascular damage ${ }^{15,16} \mathrm{We}$ decided to assess any potential association between Pro-BNP, insulin, adiponectin, leptin, and ghrelin and the appearance of proteinuria in chronic hemodialysis patients.

\section{Methods}

\section{Design}

This was a cross-sectional, prospective, observational comparative study in 57 chronic hemodialysis patients.

\section{Patients}

The Institutional Review Board of the Hospital Británico de Buenos Aires approved the present cross-sectional study. Informed consent was obtained from each patient enrolled. Fifty-seven chronic hemodialysis patients with more than 3 months under treatment were included. Patients under age 18 years, or with a history of neoplasia, acute infection, liver disease, untreated hypothyroidism, anuria, or BMI $>40 \mathrm{~kg} / \mathrm{m}^{2}$ were excluded. For the purpose of this study, anuria was defined as diuresis $<140 \mathrm{~mL} /$ day, and proteinuria $>0.15 \mathrm{~g}$ /day was considered positive. One patient was HIV-positive and one HbsAg-positive. Although in active disease, these viruses can affect adipokine levels, our two patients presented without active viral replication at the time of the study. No failedtransplant patients were included. Patients were divided in three groups according to the BMI: group A (GA), BMI $<25$ $(\mathrm{n}=22)$; GB, BMI 25-30 ( $\mathrm{n}=15)$; and GC, BMI $>30$ $(\mathrm{n}=20)$. Median age in years (range) among the groups was: GA 65 (36-83), GB 71 (26-88), and GC 63 (33-79); $P=0.61$. In addition, groups were statistically not different with respect to sex, time on hemodialysis, cause of renal disease, diabetes mellitus, hypertension, $\mathrm{C}$-reactive protein (CRP), nutritional status assessed by malnutrition inflammatory score, ${ }^{17,18}$ amount of urinary output, or nutritional status (Table 1). Measures were taken of 24-hour urinary output and proteinuria, mean intradialytic ultrafiltration rates, Pro-BNP, albumin, insulin, adiponectin, leptin, and ghrelin levels. Proteinuria and serum concentration of albumin and CRP were measured by routine procedures. For Pro-BNP, a chemiluminescence method was used (Vitros 5600; Johnson and Johnson, New Brunswick, NJ, USA), for which normal values are $<125 \mathrm{pg} / \mathrm{mL}<75$ years old and $<450 \mathrm{pg} / \mathrm{mL}$ for subjects older than 75 years. Insulin was determined by electrochemiluminescence (Cobas e411; Roche Diagnostics, Indianapolis, IN, USA), for which a normal value is $2-15 \mu \mathrm{U} /$ $\mathrm{mL}$. Homeostasis model assessment of insulin resistance (HOMA) was calculated by (insulin $\times$ glycemia) $/ 405$. Human adiponectin, leptin, and ghrelin (acyl ghrelin or active ghrelin) were determined by enzyme-linked immunosorbent assay (Merck Millipore, Billerica, MA, USA).

Blood was drawn in the fasting condition prior to the hemodialysis session. Twenty-four-hour urine samples were collected on Sundays or Mondays, depending on the dialysis schedule of each individual. Proteinuria was measured only once, in coincidence with the 24-hour urine collection. Blood and urine samples were collected in May 2012. All biochemical measurements were done at the Central Laboratory of the Hospital Británico. 
Table I Patient characteristics

\begin{tabular}{|c|c|c|c|}
\hline Variable & Group A & Group B & Group C \\
\hline $\mathrm{n}$ & 22 & 15 & 20 \\
\hline Male sex (\%) & $10(45)$ & $9(60)$ & $14(70)$ \\
\hline Diabetics (\%) & $4(18)$ & $3(20)$ & $10(50)$ \\
\hline Hypertensives (\%) & $15(68)$ & $12(80)$ & $17(85)$ \\
\hline Median age (years) & 65 & 71 & 63 \\
\hline Range & $36-83$ & $26-88$ & $33-79$ \\
\hline Median time on & 12 & 26 & 15.5 \\
\hline \multicolumn{4}{|l|}{ HD (months) } \\
\hline Range & $4-101$ & $9-92$ & $4-55$ \\
\hline BMI (mean \pm SD) & $21.3 \pm 2.4^{*}$ & $27.6 \pm 1.4^{*}$ & $33.9 \pm 4.2^{*}$ \\
\hline Median MIS & 5.5 & 4 & 3 \\
\hline Range & $|-2|$ & $2-8$ & $0-13$ \\
\hline \multicolumn{4}{|l|}{ Causes of ESRD } \\
\hline Glomerulonephritris & 8 & 7 & 11 \\
\hline Diabetes & 2 & 2 & 3 \\
\hline Nephroangiosclerosis & 7 & 3 & 4 \\
\hline Obstructive uropathy & I & - & I \\
\hline Interstitial nephritis & 1 & I & I \\
\hline Polycystic kidney disease & 3 & 2 & 0 \\
\hline Median C-reactive & 1.2 & I.I & I.I \\
\hline \multicolumn{4}{|l|}{ protein $(\mathrm{mg} / \mathrm{dL})$} \\
\hline Range & $0.50-12$ & $0.20-8$ & $0-4.5$ \\
\hline Median urinary & 690 & 660 & 840 \\
\hline \multicolumn{4}{|l|}{ output (mL/day) } \\
\hline Range & $140-1780$ & $160-1800$ & $140-2840$ \\
\hline Median proteinuria (g/day) & 0.72 & 0.94 & 1.53 \\
\hline Range & $0.20-2.73$ & $0.15-3.94$ & $0.30-14$ \\
\hline
\end{tabular}

Note: $* P<0.001$.

Abbreviations: HD, hemodialysis; BMI, body mass index; SD, standard deviation; MIS, malnutrition inflammatory score; ESRD, end-stage renal disease.

\section{Hemodialysis aspects}

Thrice-weekly hemodialysis sessions were performed using high-flux biocompatible membranes (Polyflux $21 \mathrm{R}$; Gambro, Lund, Sweden/Sureflux 190; Nipro, Osaka, Japan) and bicarbonate bath, with a mean blood flow $(\mathrm{Qb})$ of $450 \pm 50 \mathrm{~mL} /$ minute, dialysate flow (Qd) of $500 \mathrm{~mL} /$ minute, and a mean duration per session of $4.0 \pm 0.5$ hours. The ultrafiltration rate employed in this study was the one registered by automatic dialysis machines (Surdial 190; Nipro/Diamax; Nipro) when the blood samples were collected.

\section{Medications}

Most of the patients were on angiotensin-converting enzyme inhibitors, angiotensin II-receptor blockers, beta-blockers, aspirin, and other commonly used drugs at stage 5 chronic renal disease, such as calcium salts, potassium chelators, erythropoietin, intravenous L-carnitine, intravenous iron, statins, omeprazole, folic acid, vitamins, and benzodiazepines.

\section{Statistics}

Results are expressed as the median (range), unless explained otherwise. Fisher's exact test or $\chi^{2}$ were employed for categorical variables. For continuous variables, the MannWhitney test was used, and for intervariable correlations Spearman's rank correlation coefficient $(\rho)$ was calculated. $P$-values $\leq 0.05$ were considered significant. In Table 3, for comparisons of different variables according to BMI, $\chi^{2}$ coefficients were calculated and the Kruskal-Wallis test was employed.

\section{Results}

Patient characteristics are depicted in Table 1. Only patients with daily positive diuresis were included ( $>140 \mathrm{~mL} /$ day). Proteinuria was virtually present in $100 \%$ of the dialysis population when considering $0.15 \mathrm{~g}$ /day as the cutoff. Hypertensive subjects numbered 44 (77.2\%): GA, 15 (68\%); GB, 12 (80\%); GC, 17 (85\%). Seventeen diabetic patients were identified $(30 \%)$ : GA, four $(18 \%)$; GB, three $(20 \%)$; $\mathrm{GC}$, ten $(50 \%) ; P=0.11$. Noteworthy was the fact that in $\mathrm{GC}$, diabetic nephropathy was the cause of chronic kidney disease in only three patients, compared to two in GA and two in GB (Table 1). Diabetes mellitus was associated with a higher BMI, proteinuria, and diabetes, although these findings were not significant. No groups were statistically different as to inflammatory status assessed by CRP (Table 1). Urinary output was statistically higher in GC compared to GA: 840 (140-2840) $\mathrm{mL} /$ day versus (vs) $690(140-1780) \mathrm{mL} /$ day; $P=0.0188$ (Table 4). Proteinuria was significantly higher in GC vs GA: $1.5 \mathrm{~g} /$ day, range $0.30-14$ vs $0.72 \mathrm{~g} /$ day, range $0.1-2.7$; $P<0.01$ (Figure 1); and correlated significantly with leptin levels in GA $(\rho=0.47, P<0.05)$ (Table 2$)$. In GA, elevated levels of Pro-BNP, adiponectin, and ghrelin were associated with lower degrees of proteinuria, and significant negative adiponectin-leptin, significant positive adiponectin-ProBNP correlations (Tables 1-3) were found. A moderate negative nonsignificant leptin-ghrelin $(\rho=-0.38, P=0.14)$ correlation was also encountered. As BMI increased in GB and GC, Pro-BNP, adiponectin and ghrelin levels gradually decreased significantly, while proteinuria, leptin, insulin, and HOMA increased (Table 2). In GC, leptin levels were significantly elevated compared to GA and GB, and displayed a significant correlation with insulin $(\rho=0.52, P=0.03)$ and HOMA ( $\rho=0.52, P=0.03)$. Moreover, in GA the correlation between ghrelin and Pro-BNP was positive but nonsignificant ( $\rho=0.36, P=0.16)$, but was significant in GC $(\rho=0.51$, $P=0.03)$. Finally, leptin-Pro-BNP displayed a significant negative correlation in GA $(\rho=-0.74, P<0.001)$ and a 


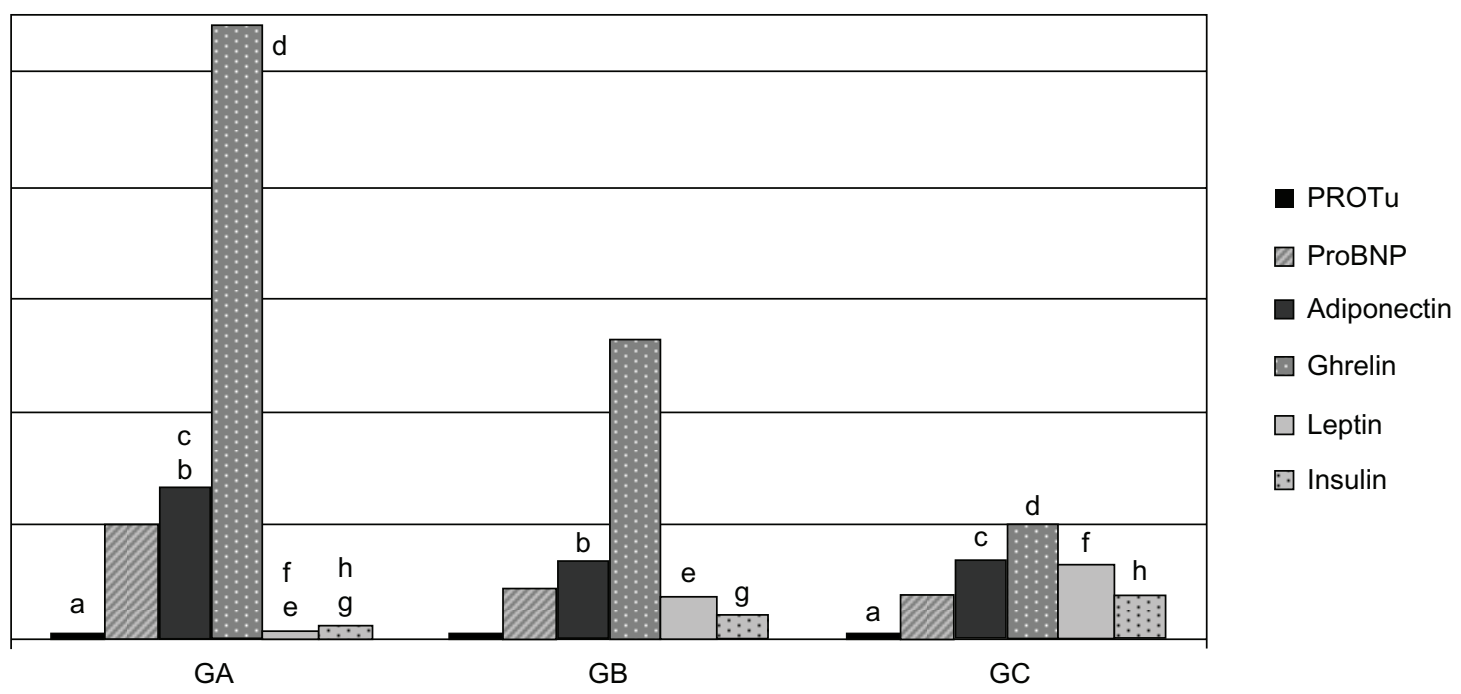

Figure I Results expressed by Group (G) as the median. Proteinuria (PROTu) GA 0.72 g/day, GB 0.94 g/day, GC I.53 g/day; Pro-brain natriuretic peptide (Pro BNP) GA $49.7 \times 10^{2} \mathrm{pg} / \mathrm{mL}$, GB $21.8 \times 10^{2} \mathrm{pg} / \mathrm{mL}$, GC $20.4 \times 10^{2} \mathrm{pg} / \mathrm{mL}$; Adiponectin GA $66.85 \mathrm{ug} / \mathrm{mL}, \mathrm{GB} 34.23 \mathrm{ug} / \mathrm{mL}$, GC $34.82 \mathrm{ug} / \mathrm{mL} ; \mathrm{Ghrelin} \mathrm{GA} 270.55 \mathrm{ug} / \mathrm{mL}, \mathrm{GB}$ I $33.41 \mathrm{ug} / \mathrm{mL}$, GC $48.55 \mathrm{ug} / \mathrm{mL}$; Leptin GA $3.8 \mathrm{ug} / \mathrm{mL}$, GB $18.6 \mathrm{ug} / \mathrm{mL}$, GC $32.8 \mathrm{ug} / \mathrm{mL}$; Insulin GA $7.00 \mathrm{uU} / \mathrm{mL}, \mathrm{GB}$ II.5 uU/mL, GC $19.5 \mathrm{uU} / \mathrm{mL}$.

Notes: a, e, g: $P<0.05$; b, d, f, h: $P<0.0$ l; c: $P=0.000$ I.

nonsignificant negative correlation in GB and GC (Table 3). Significant intergroup differences are outlined in Table 4.

\section{Discussion}

Our study shows that proteinuria is a frequent event in chronic hemodialysis that worsens as BMI increases, reinforcing our previous findings. ${ }^{8}$ This phenomenon occurs in association with an increase in leptinemia and insulin resistance, coupled with a significant decrease in Pro-BNP, adiponectin, and ghrelin levels. Though there were more diabetics in the obese group, diabetic nephropathy was not different as the cause of end-stage renal disease among the three groups (Table 1). Noteworthy was the fact that daily diuresis was statistically higher in obese individuals, which could have been associated with hyperfiltration due to heavier proteinuria. This finding could also be a partial explanation of the lower Pro-BNP and adiponectin levels found in our obese population, which were independent of the ultrafiltration rates reported (Table 2). The significant positive correlation that Pro-BNP displayed with adiponectin in patients with $\mathrm{BMI}<20$ was lost in the obese, but the positive correlation was maintained. In addition, the positive nonsignificant ghrelin-Pro-BNP correlation in GA strengthened significantly in obesity (Tables 1-3). Finally, heavy proteinuria measurements correlated nonsignificantly with inflammation and worse nutritional status, although significantly higher albumin levels were found in obese patients (Tables 1-3). In contrast to other publications, our correlations between adiponectin, leptin, or ghrelin levels and CRP were strong but not significant. ${ }^{11,16,17}$

We have previously shown that proteinuria is associated with an increase in CRP in hemodialysis patients, a finding that could not be fully confirmed again in this work. ${ }^{8}$ It has been speculated that adiponectin and Pro-BNP may play different roles according to BMI in a coordinated fashion. In agreement with our former report, Pro-BNP and adiponectin measurements were elevated in subjects with BMI $<20$. These higher titers may be the cause of lower proteinuria concentrations. In this regard, adiponectin has been demon-

Table 2 Blood measurements and ultrafiltration rates in all groups

\begin{tabular}{lllllllll}
\hline Group & $\begin{array}{l}\text { Albumin } \\
(\mathbf{g} / \mathbf{d L})\end{array}$ & UF $(\mathbf{L})$ & $\begin{array}{l}\text { Pro-BNP } \\
(\mathbf{p g} / \mathbf{m L})\end{array}$ & $\begin{array}{l}\text { Insulin } \\
(\mu \mathrm{U} / \mathbf{m L})\end{array}$ & HOMA & $\begin{array}{l}\text { Leptin } \\
(\mu \mathrm{g} / \mathbf{m L})\end{array}$ & $\begin{array}{l}\text { Adiponectin } \\
(\mu \mathrm{g} / \mathbf{m L})\end{array}$ & $\begin{array}{l}\text { Ghrelin } \\
(\mu \mathrm{g} / \mathbf{m L})\end{array}$ \\
\hline $\mathrm{A}$ & $3.70^{\mathrm{a}}$ & 2.0 & 4970 & $7.00^{\mathrm{a}, \mathrm{b}}$ & $1.30^{\mathrm{b}, \mathrm{c}}$ & $\left.3.8\right|^{\mathrm{b}, \mathrm{d}}$ & $66.85^{\mathrm{b}, \mathrm{e}}$ & $270.55^{\mathrm{b}}$ \\
& $(2.2-4.9)$ & $(0.8-4)$ & $(216-234000)$ & $(2-44)$ & $(0.3-22.4)$ & $(0.78-69.6)$ & $(21.7-178.1)$ & $(25-784.8)$ \\
$\mathrm{B}$ & 3.8 & 2.5 & 2180 & $11.50^{\mathrm{a}}$ & $2.50^{\mathrm{c}}$ & $18.60^{\mathrm{d}}$ & $34.23^{\mathrm{e}}$ & 133.41 \\
& $(3.2-4.4)$ & $(0.8-4)$ & $(226-102000)$ & $(4-38)$ & $(1.10-9.30)$ & $(4.70-47.40)$ & $(1.56-120.24)$ & $(25-514.7)$ \\
$\mathrm{C}$ & $3.85^{\mathrm{a}}$ & 3.0 & 2040 & $19.50^{\mathrm{b}}$ & $3.75^{\mathrm{b}}$ & $32.80^{\mathrm{b}}$ & $34.82^{\mathrm{b}}$ & $48.54^{\mathrm{b}}$ \\
& $(3.4-4.9)$ & $(0.5-4.0)$ & $(139-166000)$ & $(5.0-155.0)$ & $(1.0-59.3)$ & $(0.78-124.5)$ & $(12.85-89.5)$ & $(16.54-357.34)$ \\
\hline
\end{tabular}

Notes: ${ }^{\mathrm{a}} P=0.02 ;{ }^{\mathrm{b}} P=0.000 \mathrm{I} ;{ }^{\mathrm{c} P}=0.03 ;{ }^{\mathrm{d}} P=0.01 ;{ }^{\mathrm{e}} P=0.003$. The numbers in brackets are ranges.

Abbreviations: UF, ultrafiltration; Pro-BNP, pro-brain natriuretic peptide; HOMA, homeostasis model assessment of insulin resistance. 
Table 3 Correlations between adipokines and other variables in groups (G) A and C

\begin{tabular}{|c|c|c|}
\hline \multirow[t]{2}{*}{ Variable } & \multirow{2}{*}{$\frac{\text { GA, BMI }<25}{\rho ; P}$} & \multirow{2}{*}{$\begin{array}{l}\text { GC, BMI }>30 \\
\rho ; P\end{array}$} \\
\hline & & \\
\hline Leptin-proteinuria & $0.47 ;<0.05$ & $-0.15 ; 0.57$ \\
\hline Leptin-Pro-BNP & $-0.74 ; 0.001$ & $-0.35 ; 0.17$ \\
\hline Leptin-insulin & $0.34 ; 0.2$ & $0.52 ; 0.03$ \\
\hline Leptin-HOMA & $0.25 ; 0.35$ & $0.52 ; 0.03$ \\
\hline Leptin-adiponectin & $-0.54 ; 0.03$ & $-0.23 ; 0.37$ \\
\hline Adiponectin-Pro-BNP & $0.59 ; 0.02$ & $0.23 ; 0.78$ \\
\hline Ghrelin-Pro-BNP & $0.37 ; 0.16$ & $0.5 I ; 0.03$ \\
\hline Proteinuria-insulin & $0.27 ; 0.32$ & $-0.27 ; 0.29$ \\
\hline Proteinuria-MIS & $-0.26 ; 0.34$ & $0.32 ; 0.21$ \\
\hline Proteinuria-CRP & $-0.24 ; 0.36$ & $0.31 ; 0.23$ \\
\hline Proteinuria-adiponectin & $-0.08 ; 0.78$ & $-0.07 ; 0.78$ \\
\hline Proteinuria-ghrelin & $-0.12 ; 0.66$ & $0.05 ; 0.84$ \\
\hline
\end{tabular}

Abbreviations: Pro-BNP, pro-brain natriuretic peptide; HOMA, homeostasis model assessment of insulin resistance; MIS, malnutrition inflammatory score; CRP, C-reactive protein; $\rho$, Spearman's rank correlation coefficient; BMl, body mass index.

strated to play antiproteinuric effects. However, elevated ProBNP levels have been employed to assess high-risk diabetics in the development of coronary artery disease, have been correlated with microalbuminuria in heart-failure patients, are associated with echocardiographic patterns similar to the ones we reported in a previous study by our group, and have been proposed as useful tools to identify chronic kidney disease patients in whom sodium restriction can decrease blood pressure and proteinuria. ${ }^{8,18}$ However, in none of these settings was a causal effect of Pro-BNP on proteinuria assessed; not even adiponectin, whose secretion is dependent on Pro-BNP levels and has proven antiproteinuric effects. ${ }^{19}$ Finally, despite ProBNP and adiponectin having been widely studied, no literature data exist linking these two molecules and proteinuria in hemodialysis. One would expect that elevated Pro-BNP levels would be associated with proteinuria in low-BMI subjects, in contrast to our findings. To explain this apparent contradiction, we have suggested that in patients with low BMI, the usually

Table 4 Statistical differences among the different groups

\begin{tabular}{|c|c|c|c|c|}
\hline \multirow[t]{2}{*}{ Variable } & \multirow{2}{*}{$\begin{array}{l}\text { GA } \\
\text { BMI }<25\end{array}$} & \multirow{2}{*}{$\frac{\text { GB }}{\text { BMI 25-30 }}$} & \multirow{2}{*}{$\frac{\text { GA }}{\text { BMI }<25}$} & \multirow{2}{*}{$\frac{\text { GC }}{\text { BMI }>30}$} \\
\hline & & & & \\
\hline Albumin & 0.1956 & & 0.0207 & \\
\hline Proteinuria & $0.37 \mid 4$ & & 0.0108 & \\
\hline Urinary output & 0.9175 & & 0.0188 & \\
\hline Insulin & 0.0235 & & 0.0004 & \\
\hline HOMA & 0.0298 & & 0.0004 & \\
\hline Leptin & 0.0125 & & 0.0011 & \\
\hline Adiponectin & 0.0039 & & 0.0001 & \\
\hline Ghrelin & 0.0831 & & 0.0007 & \\
\hline
\end{tabular}

Note: Significant statistical difference, $P<0.05$.

Abbreviations: HOMA, homeostasis model assessment of insulin resistance; $\mathrm{G}$, group; BMI, body mass index. high encountered Pro-BNP levels may stimulate adiponectin secretion, exerting a protective compensatory cardiovascular effect. This is the first report to document elevated levels of the Pro-BNP-adiponectin binomial and low proteinuria in chronic hemodialysis patients with low BMI. Although not significant, as BMI increases, Pro-BNP and adiponectin concentrations decrease and proteinuria worsens. It is believed that interpretations of adiponectin associations with proteinuria should be based on the context where the studies were performed, as their effects can be seen as a marker of disease progression or as a causative factor for proteinuria. ${ }^{19}$ Regrettably, in many clinical studies on nephrotic syndrome and chronic kidney disease, BMI has not been considered. ${ }^{20,21}$ Adiponectin has been proposed to reduce proteinuria by acting on both the endothelium and the podocyte. It accomplishes these actions by decreasing endothelin 1 , plasminogen-activating inhibitor 1 , and oxidative stress, and by increasing nitric oxide in the kidney. ${ }^{22,23}$

Ghrelin is a peptide involved in food intake and energy balance, the kidney being an important site for its clearance and degradation. ${ }^{14,24}$ Acylated or active ghrelin and des-acyl ghrelin are the two main circulating molecular forms. More than $90 \%$ of total ghrelin is des-acyl ghrelin. ${ }^{25}$ Acylated ghrelin is involved in growth-hormone secretion and is reduced by feeding and increased by fasting. ${ }^{25,26}$ Low ghrelin is observed in proanorectic situations and in insulinresistant scenarios as in hypertension and type 2 diabetes..$^{27,28}$ Low ghrelin concentrations are associated with an increased mortality risk in hemodialysis patients. ${ }^{16}$ Active ghrelin levels are also decreased in obese subjects, ${ }^{29}$ in agreement with our study. Our study confirms the fact that active ghrelin correlated positively with adiponectin and with Pro-BNP, and inversely with obesity, insulin, and leptin ${ }^{16}$ (Table 3 ). Ghrelin also has cardioprotective effects. ${ }^{16,30}$ Ghrelin, adiponectin, and Pro-BNP may play additional and different protective effects on the cardiovascular system depending on the BMI, as these molecules show a similar coherent pattern of distribution with regard to BMI. ${ }^{10,16}$ No data have assessed ghrelin effects on proteinuria, and even less when BMI is added to this evaluation. One study by Ueno et al demonstrated in Japanese diabetics an inverse relationship between ghrelin and BMI and between ghrelin and the severity of diabetic nephropathy, but a direct association between ghrelin and proteinuria has not been clearly outlined. ${ }^{31} \mathrm{We}$ have found that an association exists between BMI, ghrelin, and proteinuria. It is possible to hypothesize that the antiinflammatory and energy-sparing actions that high ghrelin and adiponectin concentrations achieve may in part be due to 
a decrease in proteinuria. Interestingly, as acylated ghrelin is decreased in anabolic situations as feeding and increased in catabolic conditions as fasting, parallels can be drawn with obesity and proteinuria, respectively. Whether these findings could be ascribed to a causal effect of these molecules or to a consequence of BMI changes or other variables such as malnutrition or inflammation in hemodialysis subjects is yet to be determined. These combined significant correlations that Pro-BNP and adiponectin display in the low BMI tertile, and between Pro-BNP and ghrelin in the obese, with respect to proteinuria, may suggest that Pro-BNP could be a biomarker to focus on. As mentioned, Pro-BNP changes its actions according to BMI. ${ }^{8}$

In addition, we have shown that high leptin and insulin levels are associated with proteinuria as BMI increases, while Pro-BNP, adiponectin, and ghrelin tend to decrease. Moreover, insulin resistance and obesity are associated with high urinary protein levels. Interestingly, leptin and insulin displayed an inverted concentration pattern with respect to Pro-BNP, adiponectin, and leptin both in low- and high-BMI groups (Figure 1). Leptin inhibits adiponectin secretion, and hyperleptinemic satiety-inducing effects are accomplished by preventing an increase of plasma ghrelin. ${ }^{32,33}$ Hyperleptinemia is also associated with hyperinsulinemia and insulin resistance, a common finding in mild-to-moderate chronic kidney disease, an independent predictor of cardiovascular mortality linked to protein energy-wasting and inflammation. ${ }^{34-36}$ It has been proposed that leptin may play a key role in obesity hypertension, acting as a pressure- and volume-regulating factor by stimulating the sympathetic nervous system. ${ }^{37,38}$ However, as hypertension was not different among the three groups, we presume this action on proteinuria may be independent of hypertensive mechanisms. Pro-BNP could play a key role in this regard. To our knowledge, no data exist in the literature about the interactions between leptin and ProBNP in dialysis patients or with respect to proteinuria. However, leptin by itself can cause glomerulosclerosis and proteinuria. ${ }^{13}$ Whether in obese hemodialyzed subjects proteinuria is due to a decrease in Pro-BNP-adiponectin and/or ghrelin protective actions or to an increase in leptin or insulin resistance cannot be ascertained from the findings of this manuscript.

Among the limitations of our study, as a crosssectional design, no conclusions can be drawn with regard to the outcome of these findings. Moreover, the number of patients was too low to raise firm conclusions. Virtually all subjects were on antihypertensive medications (particularly angiotensin-converting enzyme inhibitors or angiotensin-receptor blockers), which could have certainly influenced the degree of proteinuria. It is not known whether proteinuria should be considered a risk factor of cardiovascular disease in dialysis. However, in our opinion, no reason exists to exclude proteinuria as a variable to be studied in this population, considering the important role it plays as a cardiovascular risk factor in predialysis chronic kidney disease. The roles of the molecules assessed in the present work as causes, consequences, or mere biomarkers of proteinuria remain to be determined in larger prospective studies.

In conclusion, proteinuria appears to be a frequent event in hemodialysis that worsens as BMI increases and is not related to diabetic nephropathy. In patients with low BMI, higher adiponectin, ghrelin, and Pro-BNP levels are associated with lower proteinuria and leptinemia. In obesity, hyperleptinemia and hyperinsulinemia predominate; whether decreased adiponectin-ghrelin-Pro-BNP and/or elevated leptin-insulin levels aggravate proteinuria is yet to be determined.

\section{Disclosure}

The authors report no conflicts of interest in this work.

\section{References}

1. de Zeeuw D. Albuminuria: a target for treatment of type 2 diabetic nephropathy. Semin Nephrol. 2007;27:172-181.

2. Amann K, Wanner C, Ritz E. Cross-talk between the kidney and the cardiovascular system. J Am Soc Nephrol. 2006;17:2112-2119.

3. Go A, Chertow G, Fan D, McCulloch C, Hsu C. Chronic kidney disease and the risks of death, cardiovascular events, and hospitalization. NEngl J Med. 2004;351:1296-1305.

4. Anavekar NS, McMurray JJ, Velazquez EJ, et al. Relation between renal dysfunction and cardiovascular outcomes after myocardial infarction. N Engl J Med. 2004;351:1285-1295.

5. Lattanzio MR, Weir MR. Have we fallen off target with concerns surrounding dual RAAS blockade? Kidney Int. 2010;78:539-545.

6. de Zeeuw D, Remuzzi G, Parving HH, et al. Proteinuria, a target for renoprotection in patients with type 2 diabetic nephropathy: lessons from RENAAL. Kidney Int. 2004;65:2309-2320.

7. Becker B, Kronenberg F, Kielstein JT, et al. Renal insulin resistance syndrome, adiponectin and cardiovascular events in patients with kidney disease: the mild and moderate kidney disease study. J Am Soc Nephrol. 2005;16:1091-1098.

8. Trimarchi H, Muryan A, Dicugno M, et al. Proteinuria: an ignored marker of inflammation and cardiovascular disease in chronic hemodialysis. Int J Nephrol Renovasc Dis. 2012;5:1-7.

9. Trimarchi H, Muryan A, Campolo-Girard V, et al. Elevated pro-brain natriuretic peptide, troponin $\mathrm{T}$ and malnutrition inflammatory score in chronic hemodialysis patients with overt cardiovascular disease. Nephron Clin Pract. 2011;117:c198-c205.

10. Trimarchi H, Muryan A, Dicugno M, et al. Adiponectin cardiovascular controversies in hemodialysis may be subjected to variations in body mass index. Hemodial Int. 2011;15:477-484.

11. Mafra D, Jolivot A, Chauveau P, et al. Are ghrelin and leptin involved in food intake and body mass index in maintenance hemodialysis? J Renal Nutr. 2010;20:151-157. 
12. Don BR, Rosales LM, Levine NW, Mitch W, Kaysen GA. Leptin is a negative acute phase protein in chronic hemodialysis patients. Kidney Int. 2001;59:1114-1120.

13. Wolf G, Chen S, Han DC, Ziyadeh FN. Leptin and renal disease. Am J Kidney Dis. 2002;39:1-11.

14. Wren AM, Seal LJ, Cohen MA, Brynes AE, Frost GS, Murphy KG. Ghrelin enhances appetite and increases food intake in humans. J Clin Endocrinol Metab. 2001;86:5992-5995.

15. Salmon AHJ, Ferguson JK, Burford JL, et al. Loss of the endothelial glycocalyx links albuminuria and vascular dysfunction. J Am Soc Nephrol. 2012;23:1339-1350.

16. Carrero JJ, Nakashima A, Qureshi AR, et al. Protein-energy wasting modifies the association of ghrelin with inflammation, leptin, and mortality in hemodialysis patients. Kidney Int. 2011;79:749-756.

17. Slee AD. Exploring metabolic dysfunction in chronic kidney disease. Nutr Metab (Lond). 2012;9:36.

18. Reinhard H, Hansen PR, Wiinberg N, et al. NT-proBNP, echocardiographic abnormalities and subclinical coronary artery disease in high risk type 2 diabetic patients. Cardiovasc Diabetol. 2012;11:19.

19. Zoccali C, Mallamaci F. Adiponectin and leptin in chronic kidney disease: causal factors or mere risk markers? J Renal Nutr. 2011;21: 87-91.

20. Zoccali C, Mallamaci F, Panuccio V, et al. Adiponectin is markedly increased in patients with nephrotic syndrome and is related to metabolic risk factors. Kidney Int Suppl. 2003:S98-S102.

21. Kollerits B, Fliser D, Heid IM, Ritz E, Kronenberg F. Gender-specific association of adiponectin as a predictor of progression of chronic kidney disease: the Mild to Moderate Kidney Disease Study. Kidney Int. 2007;71:1279-1286.

22. Nakamaki S, Satoh H, Kudoh A, Hayashi Y, Hirai H, Watanabe T. Adiponectin reduces proteinuria in streptozotocin-induced diabetic Wistar rats. Exp Biol Med. 2011;236:614-620.

23. Sharma K, Ramachandrarao S, Qiu G, et al. Adiponectin regulates albuminuria and podocyte function in mice. J Clin Invest. 2008;118: 1645-1656.

24. Yoshimoto A, Mori K, Sugawara A, Mukoyama M, Yahata K, Suganami T. Plasma ghrelin and desacyl ghrelin concentrations in renal failure. J Am Soc Nephrol. 2002;13:2748-2752.

25. Hosoda H, Kojima M, Matsuo H, Kangawa K. Ghrelin and des-acyl ghrelin: two major forms of rat ghrelin peptides in gastrointestinal tissue. Biochem Biophys Res Commun. 2000;279:909-913.
26. Kojima M, Kangawa K. Ghrelin, an orexigenic signaling molecule from the gastrointestinal tract. Curr Opin Pharmacol. 2002;2:665-668.

27. Tschop M, Weyer C, Tataranni P, Devanarayan V, Ravussin E, Heiman M. Circulating ghrelin levels are decreased in human obesity. Diabetes. 2001;50:707-709.

28. Poykko SM, Kellokoski E, Horkko S, Kauma H, Kesaniemi YA, Ukkola O. Low plasma ghrelin is associated with insulin resistance, hypertension and the prevalence of type 2 diabetes. Diabetes. 2003;52: 2546-2553.

29. Lee CC, Lee RP, Subeq YM, Wang CH, Fang TC, Hsu BG. Fasting serum total ghrelin level inversely correlates with metabolic syndrome in hemodialysis patients. Arch Med Res. 2008;39:785-790.

30. Granata R, Isgaard J, Alloatti G, Ghigo E. Cardiovascular actions of the ghrelin gene-derived peptides and growth hormone-releasing hormone. Exp Biol Med (Maywood). 2011;236:505-514.

31. Ueno H, Shiiya T, Mizuta M, Mondal MS, Nakazato M. Plasma ghrelin concentrations in different clinical stages of diabetic complications and glycemic complications in Japanese diabetics. Endocr J. 2007;54: 895-902.

32. Rodriguez Ayala E, Pecoits-Filho R, Heimburger O, Lindholm B, Nordfors L, Stenvinkel P. Associations between plasma ghrelin levels and body composition in end-stage renal disease: a longitudinal study. Nephrol Dial Transplant. 2004;19:421-426.

33. Barazzoni R, Zanetti M, Stebel M, Biolo G, Cattin I, Guarnieri G Hyperleptinemia prevents increased plasma ghrelin concentration during short-term moderate caloric restriction in rats. Gastroenterology. 2003;124:1188-1192.

34. Kobayashi S, Maesato K, Moriya H, Ohtake T, Ikeda T. Insulin resistance in patients with chronic kidney disease. Am J Kidney Dis. $2005 ; 45 ; 275-280$.

35. Shinohara K, Shoji T, Emoto M, et al. Insulin resistance as an independent predictor of cardiovascular mortality in patients with end-stage renal disease. J Am Soc Nephrol. 2002;13:1894-1900.

36. Liao MT, Sung CC, Hung KC, Wu CC, Lo L, Lu KC. Insulin resistance in patients with chronic kidney disease. J Biomed Biotechnol. 2012;2012:691369.

37. Kshatriya S, Liu K, Salah A, et al. Obesity hypertension: the regulatory role of leptin. Int J Hypertens. 2011;2011:270624.

38. Mark AL, Agassandian K, Morgan DA, Liu X, Cassell MD, Rahmouni K. Leptin signaling in the nucleus tractus solitarii increases sympathetic nerve activity to the kidney. Hypertension. 2009;53:375-380.

\section{Publish your work in this journal}

The International Journal of Nephrology and Renovascular Disease is an international, peer-reviewed open-access journal focusing on the pathophysiology of the kidney and vascular supply. Epidemiology, screening, diagnosis, and treatment interventions are covered as well as basic science, biochemical and immunological studies. The journal welcomes

\section{Dovepress}

original research, clinical studies, reviews \& evaluations, expert opinion and commentary, case reports and extended reports. The manuscript management system is completely online and includes a very quick and fair peerreview system, which is all easy to use. Visit http://www.dovepress.com/ testimonials.php to read real quotes from published authors 